[Short Communication]

\section{A new species of the spider genus Oilinyphia (Araneae: Linyphiidae) from Thailand}

\author{
Booppa Ponksee ${ }^{1} \&$ Akio Tanikawa ${ }^{2}$
}

\author{
${ }^{1}$ Entomological Research Unit, Department of Biology, \\ Faculty of Science, Prince of Songkla University, Kor Hong, \\ Hat Yai, Songkhla, Thailand 90112 \\ E-mail: zigzagargiope@yahoo.com \\ ${ }^{2}$ Laboratory of Biodiversity Science, School of Agriculture and \\ Life Sciences, The University of Tokyo, 1-1-1, Yayoi, \\ Bunkyo-ku, Tokyo, 113-8657 Japan \\ E-mail:dp7a-tnkw@j.asahi-net.or.jp
}

\begin{abstract}
A new linyphiid species, Oilinyphia jadbounorum, is described using the specimens collected from Khuan Khao Wang Forest Park, Thailand. The only species of the genus, $O$. peculiaris, has been known from Ryukyu Islands, Japan. The discovery of this new species reveals the occurrence of the genus in Southeast Asia.
\end{abstract}

Key words - Oilinyphia jadbounorum, new species, Linyphiidae, Thailand.

The genus Oilinyphia Ono \& Saito 1989 was described based on the type species Oilinyphia peculiaris Ono \& Saito 1989 by monotypy, and no other species in this genus have been described after that (Platnick 2010). The spiders of the genus have been known only from the Ryukyu Islands, Southwest Japan. Recently, we found the second species of the genus in Khuan Khao Wang Forest Park, Thailand, and describe it as a new species.

Type specimens designated in this paper are deposited in the collection of Princess Maha Chakri Sirindhorn Natural History Museum, Prince of Songkla University, Thailand. All measurements are given in $\mathrm{mm}$.

We wish to express our heartfelt thanks to Dr. Tadashi Miyashita, the University of Tokyo, for his critical reading of the manuscript of this paper. We are deeply indebted to Mr. Petcharat Jad and Mr. Doaungboubpha Bounsavanh, who helped our field work.

Family Linyphiidae

Genus Oilinyphia Ono \& Saito 1989

Oilinyphia jadbounorum new species (Figs. 1-3)

Type series. Holotype: 우, 12-II-2009, Khuan Khao Wang Forest Park, Hat Yai, Songkhla Province, Thailand,
Booppa Ponksee leg. Paratypes: 4우 $10^{\lambda}$, same data as the holotype.

Description. Measurements. Based on the holotype 우 and 10 from paratypes, measurements in parentheses indicate the range among specimens, 우/, , in mm. Body 1.60 $\left(1.36^{-1.60) / 1.25 ~ l o n g . ~ C a r a p a c e ~} 0.59\left(0.48^{-0.63) / 0.56 ~ l o n g ; ~}\right.\right.$ $0.51(0.47-0.55) / 0.51$ wide. Length of legs [tarsus + metatarsus + tibia + patella + femur $=$ total $]: ~ I, ~ 0.35+0.53+0.45+$ $0.16+0.49=1.98 / 0.35+0.55+0.41+0.17+0.50=1.98 ;$ II, $0.38+0.55+0.52+0.17+0.55=2.17 / 0.36+0.53+0.44+$ $0.17+0.52=2.02 ; \quad$ III,$\quad 0.31+0.55+0.38+0.20+0.51=$ $1.95 / 0.31+0.42+0.33+0.15+0.42=1.63 ; \mathrm{IV}, 0.32+0.55+$ $0.55+0.18+0.66=2.26 / 0.34+0.53+0.49+0.16+0.55=$ 2.07. Abdomen $1.04(0.83-1.04) / 0.73$ long; 0.89 (0.670.90) $/ 0.65$ wide.

Carapace longer than wide [length/width $1.17\left(1.00^{-}\right.$ 1.17)/1.10]. MOA as long as wide [length/width 1.00 $\left.\left(0.95^{-1.00}\right) / 1.00\right]$. Labium longer than wide [length/width $0.44(0.39-0.44) / 0.39]$. Sternum wider than long [length/ width $0.94(0.82-0.94) / 0.87]$. Length of leg I/length of carapace $3.36(3.21-3.36) / 3.54$; tibia I-IV with two dorsal spines; position of trichobothrium on metatarsaus I (Tm I) $0.25(0.24-0.25) / 0.24$. Male palp (Fig. 3): embolus short Abdomen longer than wide [length/width 1.18 (1.071.26)/1.12], with many long hairs (Fig. 1). Epigynal opening small (Fig. 2).

Coloration and markings. Carapace dark brown, legs pale yellow. Abdomen black.

Remarks. The present new species closely resembles Oilinyphia peculiaris Ono \& Saito 1989 in general appearance, but can be easily distinguished from the latter by the shape of epigynum and male palpal organ. The epigynal opening is very wide in paculiaris but not in jadbounorum, the embolus of male palp is filiform and very long in peculiaris but short in jadbounorum.

Distribution. Known only from the type locality.

Etymology. The specific name is dedicated to $\mathrm{Mr}$. Petcharat Jad and Mr. Doaungboubpha Bounsavanh, who supported our field work.

Notes. The present new species is placed in the genus Oilynyphia by the following features: carapace dark colored and slightly longer than wide; anterior median eyes adjacent to each other and larger than anterior lateral eyes; tibia I-IV with two dorsal spines; abdomen dark colored, pear shaped, and with many long hairs.

\section{References}

Ono, H. \& Saito, H. 1989. A new linyphiid spider from the Ryukyu Islands, Southwest Japan. Bull. Natn. Sci. Mus., Tokyo, 15: 231234.

Platnick, N. I. 2010. The world spider catalog, version 10.5. American Museum of Natural History, online at http://research. amnh.org/entomology/spiders/catalog/index.html

Received April 10, 2010 / Accepted July 4, 2010 


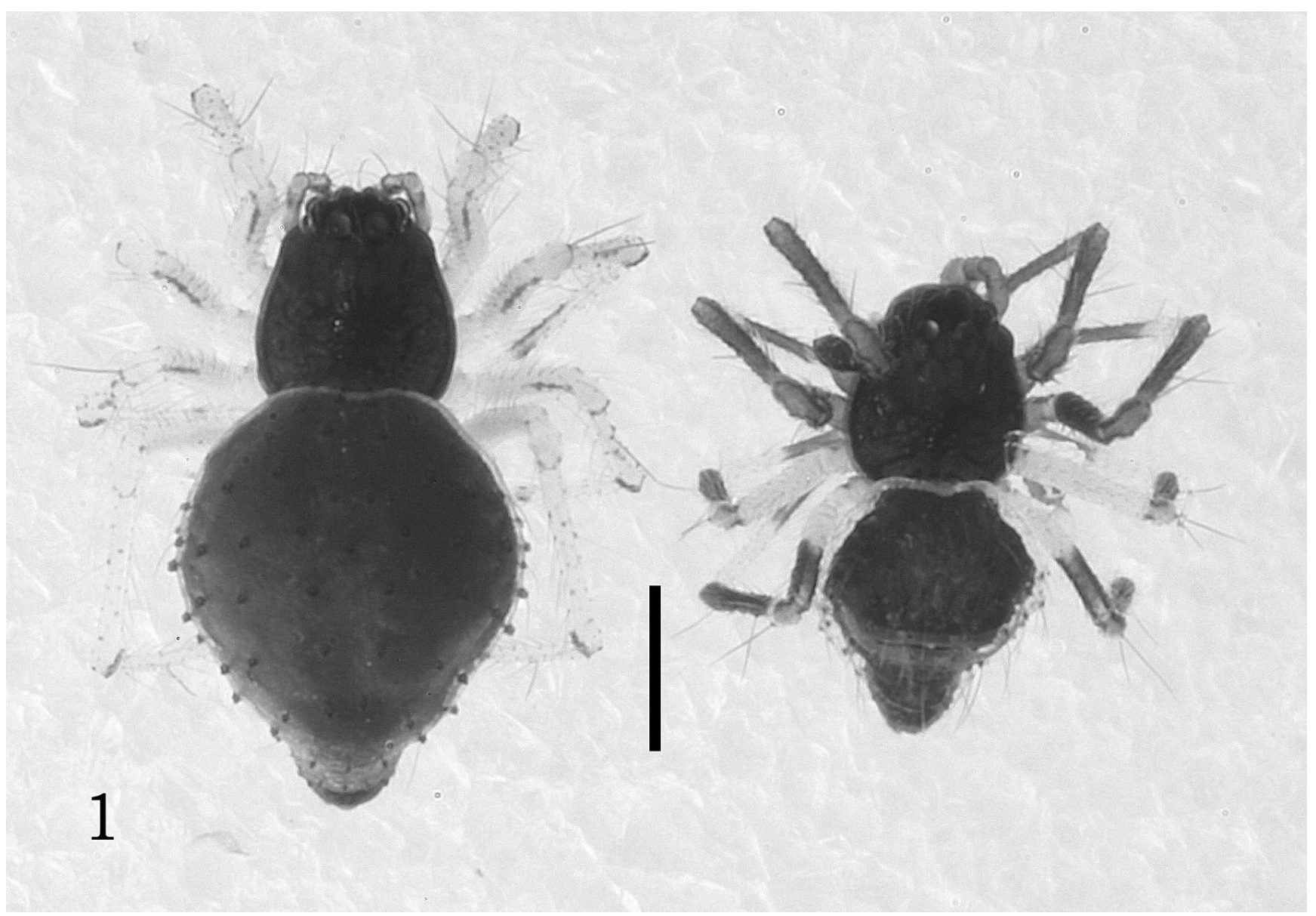

Fig. 1. Oilinyphia jadbounorum new species — left, holotype female; right, paratype male. (Scale: $0.5 \mathrm{~mm}$.)
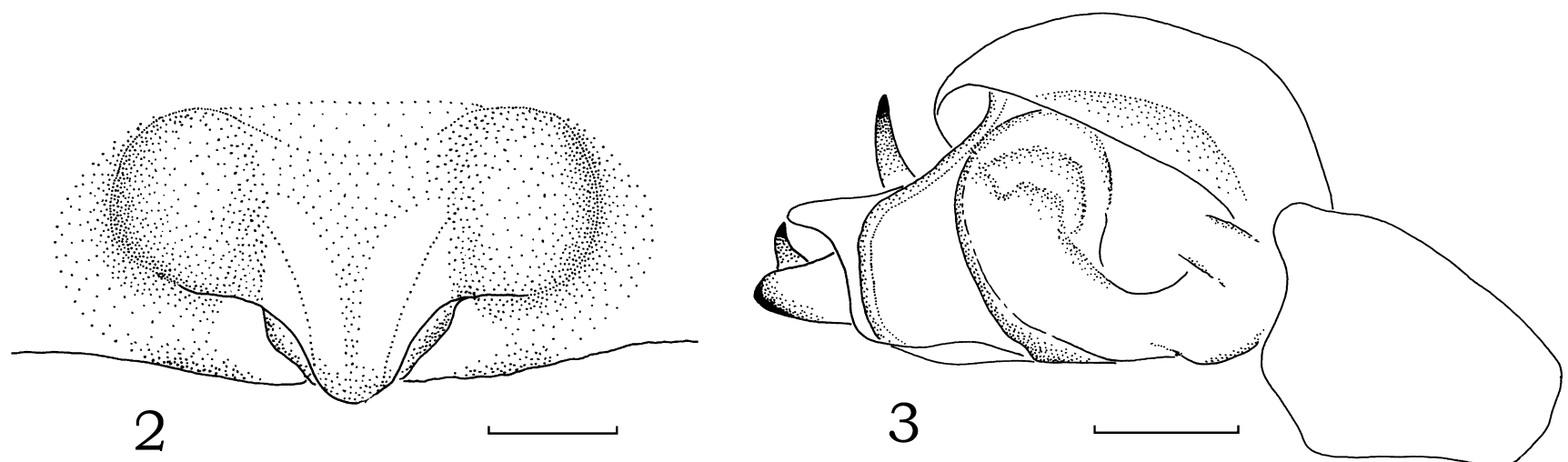

Figs. 2-3. Oilinyphia jadbounorum new species — 2, epigynum, ventral view (holotype); 3, male palp, retrolateral view (paratype). (Scales: $0.1 \mathrm{~mm}$.) 